\title{
Enzymatic Transformation and Bonding of Sulfonamide Antibiotics to Model Humic Substances
}

\author{
J. Schwarz, ${ }^{1,2}$ H. Knicker, ${ }^{3}$ G. E. Schaumann, ${ }^{2}$ and S. Thiele-Bruhn' \\ ${ }^{1}$ Soil Science, University of Trier, Behringstraße 21, 54286 Trier, Germany \\ ${ }^{2}$ Institute for Environmental Sciences, Group of Environmental and Soil Chemistry, University of Koblenz-Landau, Fortstraße 7 , \\ 76829 Landau, Germany \\ ${ }^{3}$ Institute of Natural Resources and Agrobiology of Seville, CSIC, Avenida Reina Mercedes 10, 41012 Sevilla, Spain
}

Correspondence should be addressed to S. Thiele-Bruhn; thiele@uni-trier.de

Received 1 December 2014; Accepted 29 January 2015

Academic Editor: Chengshuai Liu

Copyright (c) 2015 J. Schwarz et al. This is an open access article distributed under the Creative Commons Attribution License, which permits unrestricted use, distribution, and reproduction in any medium, provided the original work is properly cited.

\begin{abstract}
Sulfonamides are consumed as pharmaceutical antibiotics and reach agricultural soils with excreta used as fertilizer. Subsequently, nonextractable residues rapidly form in soil, which has been researched in a couple of studies. To further elucidate conditions, strength, and mechanisms of the fixation to soil humic substances, three selected sulfonamides were investigated using the biochemical oligomerization of substituted phenols as a model for the humification process. Catechol, guaiacol, and vanillin were enzymatically reacted using laccase from Trametes versicolor. In the presence of the substituted phenols alone, the concentration of sulfonamides decreased. This decrease was even more pronounced when additional laccase was present. Upon the enzymatic oligomerization of the substituted phenols to a humic-like structure the sulfonamides were sorbed, transformed, sequestered, and nonextractable bound. Sulfonamides were transformed depending on their molecular properties. Fractions of different bonding strength were determined using a sequential extraction procedure. Isolated nonextractable products were analyzed by chromatographic, spectroscopic, and calorimetric methods to identify coupling and bonding mechanisms of the sulfonamides. Differential scanning calorimetry measurements suggested cross-linking of such incorporated sulfonamides in humic oligomers. Nuclear magnetic resonance spectroscopy measurements showed clear differences between the vanillin-sulfapyridine oligomer and the parent sulfapyridine indicating bound residue formation through covalent binding.
\end{abstract}

\section{Introduction}

Sulfonamides are a group of synthetic pharmaceutical antibiotics. As a result of their prevalent consumption in human and veterinary medicine and subsequent excretion they reach agricultural soils via contaminated sewage sludge, waste water, and manure used for soil fertilization [1,2]. Antibiotics were shown to persist in soil for months so that reapplication of organic fertilizers leads to a plateau of residual concentrations [3]. Such long-term contamination of soils with bioactive antibiotics substantially increases the risk of their translocation into adjacent environmental compartments and of effects on soil microorganisms $[4,5]$. Following the application to soil the detectable concentration of sulfonamides rapidly decreases within a few hours [6-8], which process subsequently decelerates but further continues [9-11].
Nonextractable residues are formed that even resist harsh extraction methods such as pressurized liquid extraction procedures $[12,13]$ whereas mineralization of the fixed residues is low with $<2 \%[10,11]$. From an environmental perspective it is highly relevant to know whether these nonextractable and persistent residues are physically entrapped parent molecules, which would exhibit antibiotic activity after a possible remobilization, or if covalent binding along with transformation leads to the disintegration and inactivation of the sulfonamides.

However, soil as a heterogeneous matrix possesses numerous disruptive factors that hamper the elucidation of transformation pathways. The analytical determination of organic nitrogen compounds bound to soil humus is impeded in particular due to the formation of various metabolites and a large number of different modes of binding which leads 
TABLE 1: Physicochemical properties and structures of the selected sulfonamides.

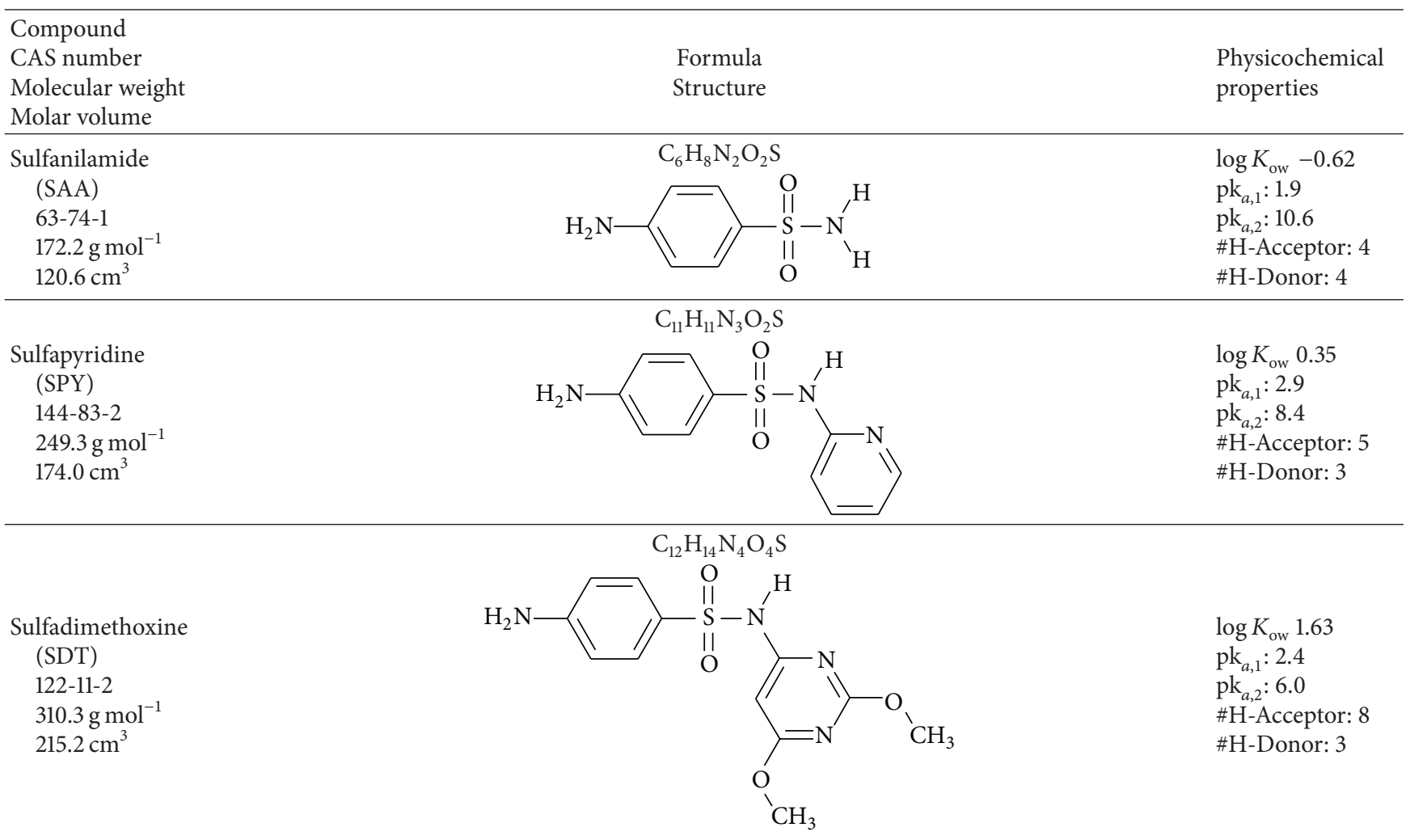

to low concentrations of each single compound $[14,15]$. It is assumed that this is also valid for $\mathrm{N}$-containing sulfonamides as well. These restrictions can be overcome using well-defined substituted phenolic compounds that represent special sites and functionalities of humic substances. These compounds are major building blocks of humic molecules [16] and were found to polymerize to humus-like substances [17]. Reacting such substituted phenols with oxidoreductase enzymes or abiotically through pedogenic oxides, hydroxides, and clay minerals $[18,19]$ serves as model to elucidate transformation reactions or modes of binding happening in soil upon humification processes.

Using that experimental approach, Bialk et al. [21, 22] and Bialk and Pedersen [23] reported enzymatically catalyzed oxidative coupling of selected sulfonamides. They found that a catalyst is needed to gain a transformation of sulfonamides in the presence of phenolic substances [21]. A significant direct oxidation of the sulfonamides sulfamethoxazole, sulfamethazine, and sulfapyridine occurred in the presence of acid birnessite, while bound residue formation was even stronger by fungal peroxidase catalyzed covalent cross coupling in the presence of o-phenols and 2,6-dimethoxyphenols, respectively [21]. Similar results were obtained when humic acid [23] or when a whole soil sample was used [24]. Also it was found that the amount of quinones in soil that can take part in the nucleophilic addition is the limiting factor in the bound residue formation of sulfonamides [24]. Binding mechanisms were identified as Michael addition, leading to the formation of anilinohydroquinones and anilinoquinones and possible further covalent linkages, while the formation of a Schiff base (imine formation) was controversially discussed [21-23, 25, 26]. Gulkowska et al. $[26,27]$ concluded that radical coupling reactions are most likely not relevant for the initial covalent bond formation.

The findings of these reports are further completed by our study. The aim was to (i) elucidate the reaction of phenolic substances with sulfonamides in the absence of a further catalyst and its dependence on the concentration and reaction time and (ii) to determine the strength and type of enzyme catalyzed immobilization with the help of a sequential extraction procedure and analytical identification of reaction products by using ${ }^{15} \mathrm{~N}$ CPMAS NMR and differential scanning calorimetry (DSC). For this purpose, three differently substituted phenols, that is, catechol, guaiacol, and vanillin, were used as model substances to determine the immobilization of three selected sulfonamides, that is, sulfanilamide (SAA), sulfapyridine (SPY), and sulfadimethoxine (SDT), in the presence and absence of the enzyme laccase from Trametes versicolor taken as biocatalyst.

\section{Materials and Methods}

2.1. Chemicals and Enzyme. Three pharmaceutical substances were selected from the group of sulfonamides that are composed of a core structure and different substituents at the sulfonamide-N (Table 1). The SAA (4aminobenzenesulfonamide) was obtained from Riedel-de 
TABLE 2: Physicochemical properties and structures of the selected phenolic model substances.

\begin{tabular}{|c|c|c|}
\hline $\begin{array}{l}\text { Compound } \\
\text { CAS number } \\
\text { Molecular weight } \\
\text { Molar volume }\end{array}$ & $\begin{array}{l}\text { Formula } \\
\text { Structure }\end{array}$ & $\begin{array}{l}\text { Physicochemical } \\
\text { properties }\end{array}$ \\
\hline \multicolumn{3}{|c|}{ Hydroxyphenol derivate } \\
\hline $\begin{array}{l}\text { Catechol } \\
\text { (Cat) } \\
120-80-9 \\
110.11 \mathrm{~g} \mathrm{~mol}^{-1} \\
86.2 \mathrm{~cm}^{3}\end{array}$ & $\begin{array}{l}\mathrm{C}_{6} \mathrm{H}_{6} \mathrm{O}_{2} \\
\mathrm{OH}\end{array}$ & $\begin{array}{l}\log K_{\mathrm{ow}} 0.88 \\
\mathrm{pk}_{a}: 9.45 \\
\text { \#H-Acceptor: } 2 \\
\text { \#H-Donor: } 2\end{array}$ \\
\hline \multicolumn{3}{|c|}{ Methoxyphenol derivatives } \\
\hline $\begin{array}{l}\text { Guaiacol } \\
\quad \text { (Gua) } \\
90-05-1 \\
124.10 \mathrm{~g} \mathrm{~mol}^{-1} \\
111.8 \mathrm{~cm}^{3}\end{array}$ & $\begin{array}{l}\mathrm{C}_{7} \mathrm{H}_{8} \mathrm{O}_{2} \\
\mathrm{OH}\end{array}$ & $\begin{array}{l}\log K_{\text {ow }} 1.32 \\
\mathrm{pk}_{a}: 10.0 \\
\text { \#H-Acceptor: } 2 \\
\text { \#H-Donor: } 1\end{array}$ \\
\hline \multicolumn{3}{|c|}{$\begin{array}{l}\mathrm{C}_{8} \mathrm{H}_{8} \mathrm{O}_{3} \\
\mathrm{OH}\end{array}$} \\
\hline $\begin{array}{l}\text { Vanillin } \\
\text { (Van) } \\
121-33-5 \\
152.20 \mathrm{~g} \mathrm{~mol}^{-1} \\
123.5 \mathrm{~cm}^{3}\end{array}$ & & $\begin{array}{l}\log K_{\mathrm{ow}} 1.21 \\
\mathrm{pk}_{a}: 7.40 \\
\text { \#H-Acceptor: } 3 \\
\text { \#H-Donor: } 1\end{array}$ \\
\hline
\end{tabular}

Haën (Seelze, Germany); SDT (4-amino-N-[2,6-dimethoxy4-pyrimidinyl] benzenesulfonamide) and SPY (4-amino$\mathrm{N}$-(2-pyridinyl) benzenesulfonamide) were obtained from Sigma-Aldrich (Steinheim, Germany). All sulfonamides had a purity of $\geq 99 \%$.

Three phenolic compounds were used for the experiments. Catechol (1,2-benzenediol), guaiacol (2-methoxyphenol), and vanillin (4-hydroxy-3-methoxybenzaldehyde) were purchased from Fluka Biochemika (Buchs, Switzerland). All substances used were of pa quality ( $\geq 97 \%)$. Structures and physicochemical properties of the substituted phenols are summarized in Table 2 . These substituted phenols have been chosen because they comprise different functional groups and are typical fragments from soil humic and fulvic acids $[16,28]$.

The native soil phenoloxidase laccase from $T$. versicolor (CAS: 80498-15-3; Enzyme Commission (EC) Number: 1.10.3.2.; $26.8 \mathrm{U} \mathrm{mg}^{-1}$ Fluka, Steinheim, Germany) was used as biocatalyst. Laccase was used in this study since many phenoloxidases naturally occur in soil [29], and cross coupling of xenobiotics to soil humus in the presence of isolated fungal enzymes has been demonstrated via in situ model systems [19]. One enzyme unit (U) corresponded to the amount of the laccase that transforms $1 \mu \mathrm{mol} 2,6$-dimethoxyphenol in 1 minute at $25^{\circ} \mathrm{C}$ and a pH of 5.0. The oxidation of 2,6-dimethoxyphenol to the colored product $3,5,3^{\prime}, 5^{\prime}$ tetramethoxy-bicyclohexyl-2,5,2 $2^{\prime} 5^{\prime}$-tetraene- $4,4^{\prime}$-dione was photometrically measured at $468 \mathrm{~nm}$ using a Shimadzu UV 1650-PC (Duisburg, Germany) spectrophotometer.

\subsection{Model Experiments}

Experiment 1. The influence of an increasing concentration of the phenolic compound on the free dissolved concentration of the sulfonamides in the absence of enzyme was investigated. Stock solutions of the three individual sulfonamides were prepared in citrate-phosphate-buffer ( $\mathrm{pH} 4.5$ ). To $0.5 \mathrm{~mL}$ of each solution between 0 and $1 \mathrm{~mL}$ of catechol or vanillin solution was added. The reaction vials were filled with buffer solution to a total volume of $2 \mathrm{~mL}$, reaching final concentrations for the substituted phenols (catechol or vanillin) of $0,0.007,0.013,0.020,0.027$, and $0.033 \mathrm{M}$ and for the sulfonamides of $0.3 \mathrm{mM}$. During the experiment time, ranging from $1 \mathrm{~h}$ to $24 \mathrm{~d}$, samples were exposed to room temperature $\left(24^{\circ} \mathrm{C} \pm 1\right)$ without shaking. Tubes were wrapped with parafilm, retarding moisture loss while allowing for gas exchange. Samples were kept in the dark and protected from photodegradation. The concentration of the sulfonamides was analyzed with HPLC.

Experiment 2. To investigate the enzymatic transformation, a sulfonamide $(1 \mathrm{mM})$ and a phenolic substance $(0.05 \mathrm{M})$ were mixed in citrate-phosphate-buffer $(\mathrm{pH} 4.5)$ in 1:50 molar ratio of sulfonamide and phenolic compound. To this laccase from $T$. versicolor was added to reach an enzyme concentration of $2 \mathrm{DMP} \mathrm{U} \mathrm{mL}^{-1}$ in total. This was done according to Wang et al. [30]. The samples were incubated for $15 \mathrm{~h}$ in the dark at a temperature of $21^{\circ} \mathrm{C}\left( \pm 1^{\circ} \mathrm{C}\right)$ and agitated on a horizontal shaker. Samples with a sulfonamide concentration of $1 \mathrm{mM}$ but without the addition of neither enzyme nor phenolic compound served as controls. All samples were prepared in triplicate and the further experimental conditions (temperature, gas exchange, and light exclusion) were similar as in Experiment 1. Samples were further analyzed using a sequential extraction procedure.

Experiment 3. A similar but slightly modified approach was used to investigate the influence of the sulfonamides on the structure of the enzymatically formed phenolic oligomer. The molar ratio of sulfonamide to catechol was changed to $1: 25$ and a higher enzyme concentration (19 DMP $\mathrm{U} \mathrm{mL}^{-1}$ ) was necessary to facilitate a longer incubation time of $3 \mathrm{~d}$. In this experiment a solid reaction product resulted after separation from the solution and air-drying. This solid product was used as received without further clean-up and analyzed by DSC.

Experiment 4. For solid state NMR analysis large amounts of enzymatic transformation products of ca. $500 \mathrm{mg}$ were required. Preexperiments showed that citrate buffer was not suitable for NMR (data not shown). Thus $0.5 \mathrm{~g}$ vanillin and $250 \mathrm{mg}$ of laccase $\left(23 \mathrm{U} \mathrm{mg}^{-1}\right)$ were weighted into $100 \mathrm{~mL}$ centrifuge tubes. To this $25 \mathrm{~mL}$ of a $1 \mathrm{mM}$ SPY solution in a formate-formic acid-buffer ( $\mathrm{pH} 4.5)$ were added and vortexed for $1 \mathrm{~min}$. Subsequently additional $25 \mathrm{~mL}$ of the SPY solution was added. The reaction vessels were locked with joints and vortexed again. Sample tubes were covered with parafilm and 
samples were kept in the dark over night at $21^{\circ} \mathrm{C}$ and were agitated on a horizontal shaker. After $24 \mathrm{~h}$ the solution was separated from the solid residue. The residue was washed with dilute formic acid and with $0.5 \mathrm{M} \mathrm{NaOH} / \mathrm{methanol}$ $(0.2 / 10 \mathrm{v} / \mathrm{v})$. The washing solutions were decanted and the remaining precipitate was air-dried. The elemental composition of selected samples was determined by dry combustion using a VarioEl (Elementar Analysensysteme GmbH, Hanau, Germany).

2.3. Sequential Extraction Procedure. The binding strength of the sulfonamides to the phenolic model substances was determined in the reaction solutions of the previously described model experiments. For that purpose a modified sequential extraction procedure was used according to Kim et al. [31] and Thiele et al. [32]. Briefly, a four-step extraction scheme was applied to reaction solutions that contained enzymatically formed precipitates. Step 1: the reaction solution was centrifuged at $3940 \mathrm{~g}$ for $30 \mathrm{~min}$ and the supernatant was filtered through a $0.45 \mu \mathrm{m}$ PTFE-Filter (Macherey-Nagel, Düren, Germany). To prevent losses, the filter was washed with $1 \mathrm{~mL}$ methanol. Step 2: the remaining precipitate was dissolved in $1 \mathrm{~mL}$ citrate buffer $(\mathrm{pH} 1.7)$ and agitated on a vortexer for $20 \mathrm{sec}$. To separate the solution from the residue the samples were centrifuged as described above. This procedure was repeated once and solutions were combined. Step 3: to the remaining solid $20 \mu \mathrm{L} \mathrm{NaOH}(0.5 \mathrm{M})$ and $1 \mathrm{~mL}$ methanol were added; the solution was vortexed and centrifuged. The solution was separated from the solid residue using a pipette. Step 4: the remaining solid was completely dissolved by the addition of $1 \mathrm{~mL}$ dimethyl sulfoxide (DMSO) and directly transferred to a vial for HPLC analyses. A $1 \mathrm{~mL}$ aliquot of each extraction step was pipetted into HPLC vials.

\subsection{Chromatographic, Spectroscopic, and Calorimetric Analysis}

2.4.1. High Performance Liquid Chromatography (HPLC) Analysis of Sulfonamides. For HPLC analysis an HP 1050 gradient elution system (Agilent, Böblingen, Germany) equipped with an Agilent diode array detector G1315B operated at $260 \mathrm{~nm}$ was used. A C18 $250 \times 4.6 \mathrm{~mm}, 100-5 \mu \mathrm{m}$ reversed phase column (Macherey-Nagel, Düren, Germany) served as stationary phase. The temperature of the column was kept at $22^{\circ} \mathrm{C}$. As mobile phase $0.01 \mathrm{M} \mathrm{H}_{3} \mathrm{PO}_{4}(\mathrm{~A})$ and

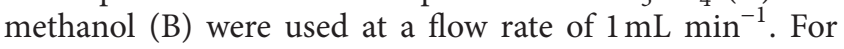
gradient elution the composition of the solvents was changed as follows: 0 to $3 \mathrm{~min} 100 \% \mathrm{~A}, 3$ to $10 \mathrm{~min}$ linear to $80 \% \mathrm{~A}$ and $20 \% \mathrm{~B}, 10$ to $22 \mathrm{~min}$ linear to $100 \% \mathrm{~B}, 22$ to $28 \mathrm{~min} 100 \% \mathrm{~B}$, 28 to $29 \mathrm{~min}$ linear to $100 \% \mathrm{~A}$, and 29 to $30 \mathrm{~min} 100 \% \mathrm{~A}$. The injection volume was $10 \mu \mathrm{L}$ and quantification was done using external standards. Detection limits were $0.03 \mu \mathrm{mol} \mathrm{L}^{-1}$ for SAA and below for SPY and SDT; further details on detection limits and recovery rates have been published elsewhere [33].

2.4.2. Cross Polarization Magic Angle Spinning Solid State Nuclear Magnetic Resonance ( ${ }^{15}$ N CPMAS NMR) Analysis. The ${ }^{15} \mathrm{~N}$ NMR spectra were acquired on a Bruker DMX
400 spectrometer (Bruker Biospin GmbH, Rheinstetten, Germany) with a frequency of $40.5 \mathrm{MHz}$ for ${ }^{15} \mathrm{~N}$, using zirconium rotors of $7 \mathrm{~mm}$ OD with Kel-F-caps that were spun at $4.5 \mathrm{kHz}$. After a contact time of $1 \mathrm{msec}, 15,000$ to 500,000 scans with a pulse delay of 1 to $10 \mathrm{sec}$ were acquired. A line broadening of 100 to $300 \mathrm{~Hz}$ was applied for the optimization of the signalto-noise ratio. About $500 \mathrm{mg}$ of solid oligomer material was used without any further prepreparations. Chemical shifts were referenced to nitromethane (0 ppm; [34]).

2.4.3. Differential Scanning Calorimetry (DSC) Analysis. Measurements of the enzymatic reacted catechol were done using DSC and according to Schaumann and LeBoeuf [35]. Measurements were carried out with a DSC Q1000 and the Universal Analysis V4.1B software for data analysis was used (both TA Instruments, Alzenau, Germany). Of each sample 3 to $5 \mathrm{mg}$ were weighed into a hermetically sealed aluminum pan. An empty hermetic aluminum pan was used as reference. The whole measuring cell was purged with nitrogen at a flow of $50 \mathrm{~mL} \mathrm{~min}{ }^{-1}$ to avoid oxidation. Heat flow and temperature calibration were conducted with indium. To reduce the influence of water, samples were airdried under light exclusion prior to DSC analysis. During the measurement the following temperature cycles were programmed: the sample was kept at $-50^{\circ} \mathrm{C}$ isothermal for $2 \mathrm{~min}$. The temperature was increased with $10 \mathrm{~K} \mathrm{~min}^{-1}$ to $110^{\circ} \mathrm{C}$ and kept for $30 \mathrm{~min}$ isothermal. The cell was cooled again to $-50^{\circ} \mathrm{C}$ and a second heating cycle was started with a rate of $10 \mathrm{~K} \mathrm{~min}^{-1}$ to $200^{\circ} \mathrm{C}$. The data from the second heating cycle in a temperature range from $-20^{\circ} \mathrm{C}$ to $200^{\circ} \mathrm{C}$ were evaluated. The first derivative of the endothermic heat flow was plotted as function of temperature. The glass transition-like step transition [36] is indicated by peaks with the maximum at the step transition temperature.

\section{Results and Discussion}

3.1. Nonenzymatic Reaction of Substituted Phenols and Sulfonamides. The influence of the substituted phenols alone on the sulfonamide concentration $(0.3 \mathrm{mM})$, without the addition of a catalyzing enzyme, was exemplarily investigated for catechol as a hydroxyphenol derivative and vanillin as a methoxyphenol derivative. Varying the concentration of the substituted phenols over a range of 0 to $0.033 \mathrm{M}$ resulted in a change in concentration for some of the sulfonamides. This is shown for catechol in Figure 1.

The concentration of free SPY decreased with increasing catechol concentration and time. The decrease was negligible after $1 \mathrm{~h}$ but increased during the time course of the experiment. After $24 \mathrm{~d}$ and at catechol concentrations $\geq 0.020 \mathrm{M}$, the SPY concentration was below the limit of detection. At each catechol concentration, the decrease in the SPY concentration $(c)$ during time $(t)$ was linear and followed a zero order decay:

$$
c=c_{0}-k \times t .
$$

Results of the model-fit are listed in Table 3. The rate coefficient $(k)$ increased with increasing concentration of catechol. 
TABLE 3: Concentrations of sulfonamides and hydroxyphenol derivate reacted in the absence or presence of laccase, and resulting rate coefficients of the dissipation of sulfapyridine (SPY), sulfadimethoxine (SDT), and sulfanilamide (SAA).

\begin{tabular}{|c|c|c|c|c|c|c|c|}
\hline sulfonamide & $c_{0}$ sulf. $\left(\mathrm{mmol} \mathrm{L}^{-1}\right)$ & $c$ phenol $\left(\mathrm{mol} \mathrm{L}^{-1}\right)$ & Laccase $\left(\mathrm{U} \mathrm{mL}^{-1}\right)$ & Kinetic model & $k\left(\mathrm{~h}^{-1}\right)$ & $R^{2}$ & SE \\
\hline \multirow{6}{*}{ SPY } & 0.075 & 0 & 0 & \multirow{8}{*}{ Zero order (1) } & 0.003 & 0.439 & 0.008 \\
\hline & 0.075 & 0.007 & 0 & & 0.047 & 0.910 & 0.035 \\
\hline & 0.075 & 0.013 & 0 & & 0.093 & 0.996 & 0.060 \\
\hline & 0.075 & 0.020 & 0 & & 0.140 & 0.950 & 0.089 \\
\hline & 0.075 & 0.027 & 0 & & 0.144 & 0.981 & 0.125 \\
\hline & 0.075 & 0.033 & 0 & & 0.156 & 0.998 & 0.144 \\
\hline SDT & 0.075 & 0.033 & 0 & & $0.131^{\mathrm{a}}$ & & \\
\hline SAA & 0.075 & 0.033 & 0 & & $0.003^{\mathrm{a}}$ & & \\
\hline $\mathrm{SPY}^{\mathrm{b}}$ & 1.00 & 0 & 48 & \multirow{3}{*}{ First order (2) } & 0.113 & 0.995 & 0.033 \\
\hline $\mathrm{SDT}^{\mathrm{b}}$ & 1.00 & 0 & 48 & & $4.2910^{-3}$ & 0.882 & 0.125 \\
\hline SAA $^{b}$ & 1.00 & 0 & 48 & & $2.9910^{-4}$ & 0.990 & 0.034 \\
\hline SPY & 1.00 & 0.050 & 2 & \multirow{3}{*}{ First order (2) } & 0.517 & 0.966 & 0.032 \\
\hline SDT & 1.00 & 0.050 & 2 & & 0.490 & 0.971 & 0.060 \\
\hline SAA & 1.00 & 0.050 & 2 & & 0.447 & 0.982 & 0.037 \\
\hline
\end{tabular}

${ }^{a}$ Degradation of SAA and SDT was measured only at one timepoint ( $\left.5 \mathrm{~d}\right)$. It was assumed that degradation followed zero order kinetics as it was determined for SPY.

${ }^{\mathrm{b}}$ Data from [20].

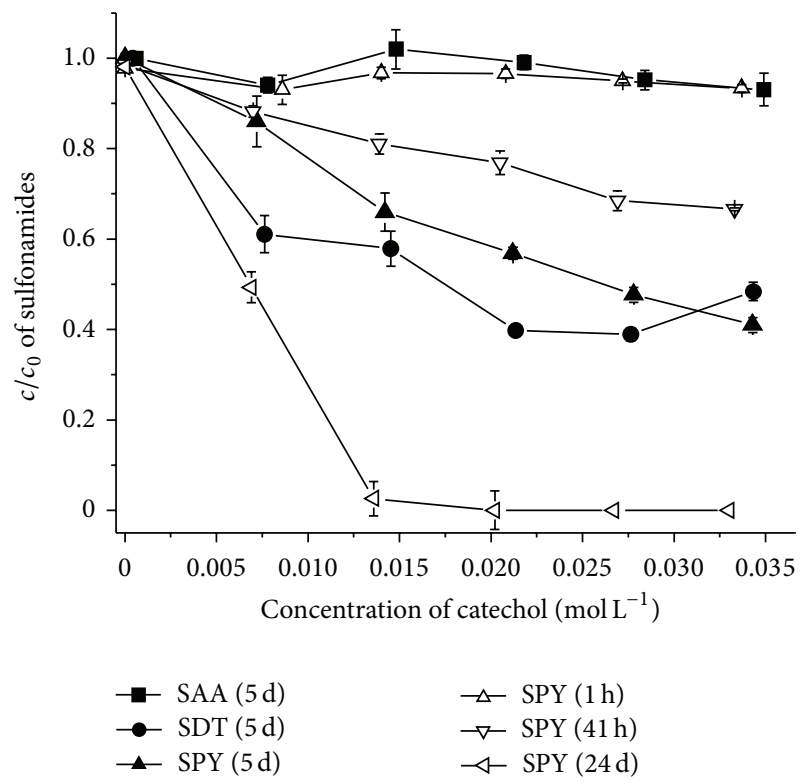

FIGURE 1: Changes of the sulfonamide concentration in dependence on the catechol concentration. The triangles indicate the data measured at different reaction time for sulfapyridine and solid symbols indicate the different sulfonamides measured after five days $(\mathrm{SPY}=$ triangles, $\mathrm{SAA}=$ squares, and SDT $=$ circles $)$. Error bars not shown are smaller than symbols.

At a catechol concentration of $0.007 \mathrm{M}$ the rate coefficient was $0.047 \mathrm{~h}^{-1}$ and increased to $0.156 \mathrm{~h}^{-1}$ at a concentration of $0.033 \mathrm{M}$. The decrease of SDT within $5 \mathrm{~d}$ was similar or even somewhat stronger compared to SPY and showed a likewise dependence on the concentration of catechol. In contrast, the free concentration of SAA after $5 \mathrm{~d}$ was still $100 \%$. The recovery rate of all three sulfonamides was also $100 \%$, when incubated without catechol; no hydrolysis and-as it was intended-no photodegradation occurred.

In contrast to catechol, the concentration of sulfonamides did not decline in the presence of vanillin during the time course of $24 \mathrm{~d}$ (not shown). This and the finding that the decrease of the sulfonamides followed zero order kinetics led to the interpretation that fractions of the substituted phenols are abiotically oxidized, whereby catechol but not vanillin can form a reactive quinone [37]. The quinone can oxidize other organic molecules by being reduced back to the parent catechol. The results show that oxidation was relevant for SPY and SDT but not for SAA, indicating that the N-heterocycle of the sulfonamides (see Table 1) was involved in the reaction.

3.2. Enzymatic Transformation of Sulfonamides. Declining sulfonamide concentrations were also determined, when combined with the enzyme laccase alone (Table 3 ). The enzymatic transformation of the sulfonamides SPY, SDT, and SAA into free dissolved degradation products has been previously reported [20] and several metabolites were proposed. These are in part similar to those reported from photodegradation [38-41] and biodegradation in soil $[42,43]$. In the study of Schwarz et al. [20], the metabolism through oxidase catalyzed free radical coupling reactions was reached at a high laccase concentration $\left(48 \mathrm{U} \mathrm{mL}^{-1}\right)$. Yet, Gulkowska et al. [26] stated that radical reactions are not relevant at lower oxidase activities.

The enzymatic reaction followed pseudo-first-order kinetics as described by

$$
c=c_{0} \times e^{(-k \times t)} .
$$

The calculated reaction-rate coefficients $(k)$ were lower compared to the coefficients determined for the transformation of the three sulfonamides with the substituted phenols alone 
TABLE 4: Percentage of sulfonamides recovered through sequential extraction after $15 \mathrm{~h}$ of enzymatic transformation with laccase from Trametes versicolor in the absence (control) and presence of substituted phenols (standard deviation in parentheses).

\begin{tabular}{|c|c|c|c|c|c|}
\hline & $\begin{array}{c}\text { Sum of all fractions } \\
=\text { recovery }\end{array}$ & $\begin{array}{l}\text { Reaction solution } \\
\quad=\text { unreacted }\end{array}$ & $\begin{aligned} & \text { Buffer pH } 1.7 \\
= & \text { easily desorbable }\end{aligned}$ & $\begin{array}{l}\mathrm{NaOH} / \text { methanol } \\
=\text { total desorbable }\end{array}$ & DMSO = sequestered \\
\hline \multicolumn{6}{|c|}{ SAA } \\
\hline Control & $98(1)$ & $98(1)$ & n.d. & n.d. & n.d. \\
\hline Catechol & $84(11)$ & n.d. & $26(10)$ & $43(13)$ & $15(13)$ \\
\hline Guaiacol & $58(8)$ & n.d. & $4(1)$ & $53(8)$ & $1(1)$ \\
\hline Vanillin & $21(7)$ & n.d. & $8(1)$ & $10(7)$ & $3(1)$ \\
\hline \multicolumn{6}{|c|}{ SPY } \\
\hline Control & $99(0.1)$ & $99(0.1)$ & n.d. & n.d. & n.d. \\
\hline Catechol & $49(10)$ & n.d. & n.d. & $39(10)$ & $10(2)$ \\
\hline Guaiacol & $33(4)$ & n.d. & $1(0)$ & $31(4)$ & $1(0)$ \\
\hline Vanillin & $27(4)$ & n.d. & $6(2)$ & $17(1)$ & $4(1)$ \\
\hline \multicolumn{6}{|c|}{ SDT } \\
\hline Control & $98(1)$ & $98(1)$ & n.d. & n.d. & n.d. \\
\hline Catechol & $94(7)$ & n.d. & $48(23)$ & $45(20)$ & $1(1)$ \\
\hline Guaiacol & $66(7)$ & n.d. & $15(2)$ & $18(2)$ & $34(6)$ \\
\hline Vanillin & $92(3)$ & $11(2)$ & $23(9)$ & $24(4)$ & 35 (11) \\
\hline
\end{tabular}

n.d.: not determined at a detection limit of $4 \mu \mathrm{mol} \mathrm{mL}^{-1}$.

(Section 3.1; Table 3). The rate coefficients declined in the same sequence SPY > SDT > SAA, showing that the influence of the sulfonamide molecular properties was similar.

The decrease in sulfonamide concentration was much stronger and substantially faster (see rate coefficients $k$ in Table 3), when the sulfonamides were incubated in the presence of both a phenolic compound and laccase. The substituted phenols act as mediators and thus enhance the effect of natural laccase [44]. The sum of the extractable fractions after $15 \mathrm{~h}$ is listed in Table 4 . In the presence of catechol and guaiacol, the total portion recovered declined in the order SDT > SAA > SPY (with differences between recoveries being significant at $P<0.05$ ). In combination with vanillin, however, the sequence was SDT $>$ SPY $\geq$ SAA (with the recoveries of SPY and SAA being not significantly different). Changes in color of the reaction solutions and the precipitation of solid products clearly indicated that phenolic oligomers were formed. This was further analytically confirmed by pyrolysis field-ionization mass spectrometry [45]. In the presence of such a phenolic oligomer polar chemicals can be immobilized with mechanisms ranging from reversible surface adsorption to the formation of cross coupling products of the substituted phenols and the sulfonamides, respectively, as it was reported for sulfonamides and other chemicals $[21,31,44]$. Based on the findings of Bialk et al. [21] using autoclaved phenoloxidases, the losses caused by sorption to the protein structure of the enzyme were considered to be negligible, while coefficients of sulfonamide sorption to the phenolic oligomers and polymers reach values similar to those obtained in the presence of soil humic acids [45]. In the control samples, the spiked sulfonamides were almost completely recovered despite a minor loss of 1 to $2 \%$ of the spiked sulfonamides due to filtration (Table 4).

A sequential extraction procedure was carried out to further investigate the efficiency of the immobilization that led to the decrease in sulfonamide concentrations. The four extraction steps were meant to determine (i) the free dissolved sulfonamides, (ii) the easily desorbed sulfonamide amounts, (iii) the totally desorbable fraction, and (iv) the sterically sequestered (entrapped) sulfonamides, while the fraction not recovered with this sequential extraction procedure was assumed to be covalently bound and/or metabolized.

The extractability of the sulfonamides varied with the chemical properties of the substituted phenols and among the different sulfonamides. It was concluded that the immobilization of the sulfonamides was influenced by the type of sulfonamide as well as the type of substituted phenol. The distribution over the four fractions of the sequential extraction was essentially similar for SPY and SAA. The SAA and SPY were no longer detectable in the reaction solution. Between 0 and $26 \%$ were easily desorbed with buffer solution of $\mathrm{pH}$ 1.7. It is assumed that the extractability partly resulted from the cleavage of less stable bonds within the phenolic oligomer, leading to a proteolytic reduction of the quinone moiety [46]. The extractability varied among the specific combinations of the sulfonamides and phenolic compounds. A substantial influence of acidic hydrolysis, as it has been reported for the sulfonamides [47], was not reflected by the in part high recoveries of the sulfonamides (Table 4). The percentage of SPY and SAA (31 to 53\%) extracted from catechol and guaiacol was clearly higher, when methanol was used. This indicates that substantial parts of these sulfonamides have been adsorbed to the phenolic oligomer. In a previous study it has been determined that the sorption of SPY, SDT, and SAA to the vanillin oligomer yielded similar sorption coefficients $\left(K_{f}\right)$ as the sorption to humic acid [45].

The DMSO extractable fraction of SAA and SPY, operationally defined as the sequestered fraction, was small ranging from 1 to $15 \%$. Also, the overall recovery of SAA and SPY by the sequential extraction scheme was well below the 


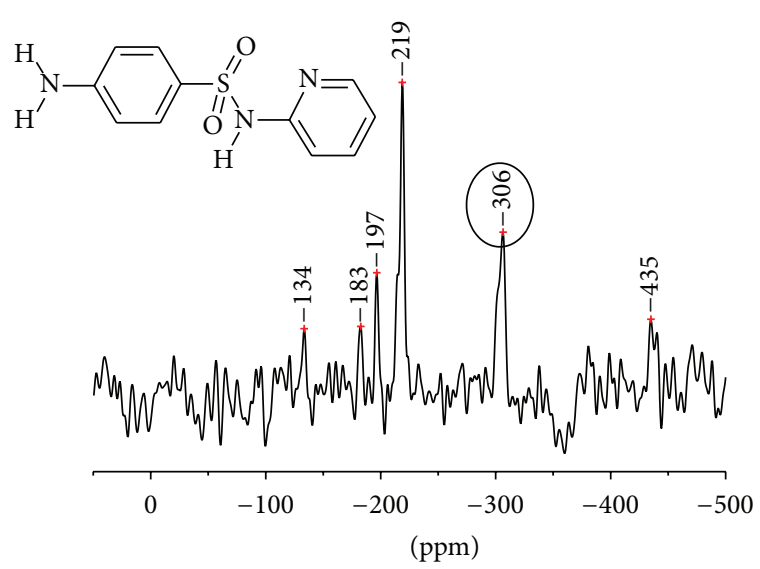

(a)

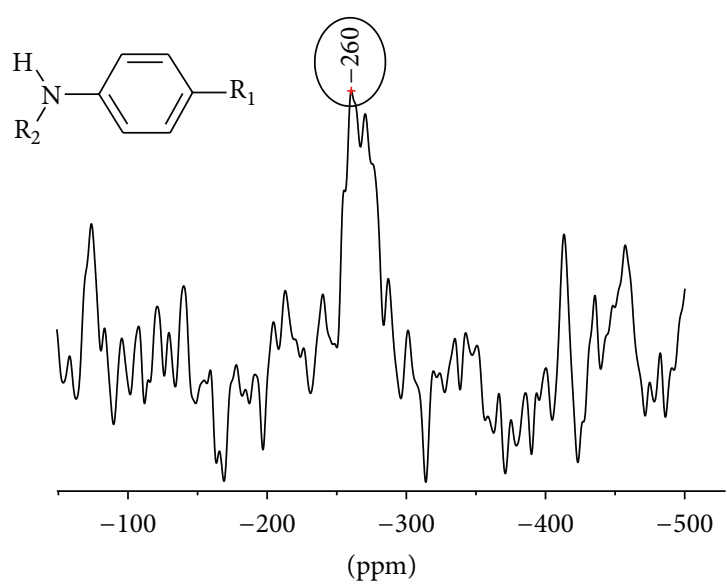

(b)

FIGURE $2:{ }^{15} \mathrm{~N}$ CPMAS NMR spectra of (a) sulfapyridine and (b) of an enzymatic coupling product of sulfapyridine with a vanillin oligomer.

recovery from control samples and declined in the order catechol $>$ guaiacol $>$ vanillin. This sequence corresponds to findings for N-containing sulfonated dyes [44]. The electron donor effect of methoxy substituents as in vanillin further enhances laccase activity due to a decreased redox potential [44]. Vanillin showed an especially strong formation of precipitate in our study (data not shown). It is suggested that the sulfonamide fractions not recovered with the sequential extraction procedure formed nonextractable residues that were covalently bound to the phenolic oligomer. The nonextractable fraction amounted to up to 73 and $79 \%$ for SPY and SAA in the presence of vanillin. Correspondingly, the emergence of nonextractable residues has been reported for sulfonamides in soil reaching up to $>80 \%$ of the initial sulfonamide content [9-11, 48]. Since the DMSO extractable fraction was small, it is concluded that nonextractability was mainly due to the formation of covalently bound residues than to the sequestration (physical entrapment) with strongly rate-limited back-diffusion in micropores as it was reported by Müller et al. [6] and Schmidt et al. [10]. The percentage of SPY recovered in the different fractions was mostly lower than for SAA. This indicates a stronger binding of SPY to the phenolic oligomers. However, it cannot be ruled out that the incomplete recovery of the sulfonamides by the extraction scheme was also due to the formation of metabolites. Yet, at the enzyme activities used in this experiment, no relevant metabolization of the sulfonamides is expected [21, 26]. Also, additional signals from metabolites have not been determined in HPLC analysis (spectra not shown). However, the identification of metabolites was not the aim of this specific experiment.

Extractability was substantially different for SDT compared to SAA and SPY (Table 4). The percentage of SDT recovered ranged between 66 and $94 \%$, when it was combined with the three phenolic substances. While the other sulfonamides were no more detectable in the reaction solution, $11 \%$ of SDT was present in the reaction solution with vanillin. Other than with SPY and SAA substantial percentages of SDT were recovered as easily and total desorbable fraction, which was especially the case in the presence of catechol with $93 \%$ of SDT recovered in the two desorbable fractions (Table 4). In the presence of guaiacol and vanillin large amounts of SDT (34 to 35\%) were sequestered in the oligomeric structure of the precipitate. This corresponds to findings of ThieleBruhn et al. [49], who determined from molecular mechanics computational chemistry modelling that SDT substantially sorbs in voids of soil organic matter. The different reactivity of SDT was not related to a different speciation. At $\mathrm{pH} 4.5$ of the reaction solution the speciation of SDT was in between that of SAA and SPY. The speciation of the sulfonamides $(+/ 0 /-)$ was $0.2 / 99.8 / 0 \%$ (SAA), $0.8 / 96.1 / 3.1 \%$ (SDT), and $2.5 / 97.5 / 0 \%$ (SPY). It is assumed that methoxyl groups attached to the $\mathrm{N}$-heterocycle of SDT (Table 1) give the molecule a sterically less flexible and thus less reactive shape. This may also be indicated by the 1.2 to 1.8 times larger molar volume of SDT compared to SAA and SPY (Table 1). Hence, a much smaller fraction of SDT (6 to 34\%) was nonextractable.

3.3. NMR Characterization of Coupling Products. To exemplarily investigate the binding mechanisms of nonextractable sulfonamides, vanillin and SPY were enzymatically reacted to form an oligomeric substance. This combination yielded an especially large amount of precipitate with an assumably high amount of nonextractable SPY (cf. Table 4). The elemental composition of the precipitate formed was $60.2 \% \mathrm{C}, 1.9 \% \mathrm{~N}$, and $0.5 \% \mathrm{~S}$. Considering the elemental composition of laccase from T. versicolor of $15.13 \% \mathrm{~N}$ and $0.496 \% \mathrm{~S}[50]$ and that of $\mathrm{SPY}$, it was estimated from the $\mathrm{N} / \mathrm{S}$ and $\mathrm{C} / \mathrm{N}$ ratios that the precipitate comprised about $10 \%$ of SPY.

The reaction product was further analyzed using ${ }^{15} \mathrm{~N}$ CPMAS NMR. The ${ }^{15} \mathrm{~N}$ NMR spectra of unaltered SPY (Figure 2(a)) and SPY in the vanillin oligomer (Figure 2(b)) differed clearly. The signal at $-306 \mathrm{ppm}$ (Figure 2(a)) indicates an $\mathrm{NH}_{2}$-group most tentatively covalently bound to a benzene ring (aniline). This signal is missing in the spectrum of the reaction product whereas a signal at $-260 \mathrm{ppm}$ assignable to amide-N appeared (Figure 2(b); [51]). The signal from aniline- $\mathrm{N}$ was shifted because the chemical surrounding 
of the nitrogen changes upon a coupling to vanillin. The observed shift of the signal from the aniline- $\mathrm{N}$ corresponds with the results of Berns et al. [52]. They reported that when sulfadiazine was transformed to trimethoxybenzoylsulfadiazine, which is a similar cross coupling product as assigned here, the signal of the aniline- $\mathrm{N}$ was shifted from $-309 \mathrm{ppm}$ to $-251 \mathrm{ppm}$. Hence, the formation of a reaction product via the aromatic amino group is indicated. Further identification of the reaction product was not possible, but it is assumed that it is most probably a structure as proposed by Berns et al. [52] or Bialk et al. [22]. Bialk et al. [22] identified a hydroxyphenol compound as a T. versicolor laccase mediated cross coupling product of SPY with protocatechuic acid. In our study the aniline- $\mathrm{N}$ was identified as the coupling moiety of SPY. Coupling to vanillin may have occurred in two different ways. First, as determined by Bialk et al. [22], aniline- $\mathrm{N}$ was bound to the aromatic ring in the paraposition of the methoxy substituent. Alternatively a cross coupling to the aldehyde-function might have happened [52]. The formation of a Schiff base as it has been identified by Bialk et al. [21] and Gulkowska et al. [25] for the oxidoreductase catalyzed cross coupling products of sulfonamides is not indicated by our results. A Schiff base with a $\mathrm{C}=\mathrm{N}$-double bond of the imine engenders in the ${ }^{15} \mathrm{~N}$ CPMAS NMR spectra a chemical shift around $-60 \mathrm{ppm}$ [51] that was not determined here.

\subsection{Differential Scanning Calorimetry (DSC) of the Catechol} Oligomer. To characterize effects of the sulfonamides on the structural properties of the phenolic oligomers DSC was carried out on example of the catechol oligomer. Glass transitions express as steps in the heat flow thermogram of the DSC-measurements, where the inflection indicates the step transition [53]. Glass transitions are common features of synthetic polymers, and weak, reversing glass transitions, better termed as step transitions, were also found for biopolymers, humic substances, and selected soil samples $[35,36]$. For the catechol oligomer we expected a step transition due to the hypothesized polymeric, humic-like structure. In Figure 3 , the first derivative of the endothermic heat flow is plotted and shows a maximum at the step transition temperature in the range of 60 to $140^{\circ} \mathrm{C}$ (indicated by arrows). The underlying processes were interpreted as step transitions because they follow the same characteristics as the reversing transitions described in Schaumann and LeBoeuf [35]. On the basis of this interpretation, the transition temperatures were interpreted as indicators of matrix rigidity [54]. Small molecules such as the sulfonamides or water can act as plasticizer which is indicated by a shift of the step transition temperature towards lower values. An antiplasticizer effect of substances within the molecule is indicated by a shift of the step transition towards higher temperatures.

The curves in Figure 3 were separated into four temperature ranges. The first range starts at $-20^{\circ} \mathrm{C}$ and ends at $20^{\circ} \mathrm{C}$, while the second range goes from $20^{\circ} \mathrm{C}$ to $60^{\circ} \mathrm{C}$. Distinct peaks with maxima at temperatures from $39^{\circ} \mathrm{C}$ to $41^{\circ} \mathrm{C}$ indicate structural changes upon heating in the catecholcore structure units that were identically found for all investigated samples. Another transition occurred as a broad

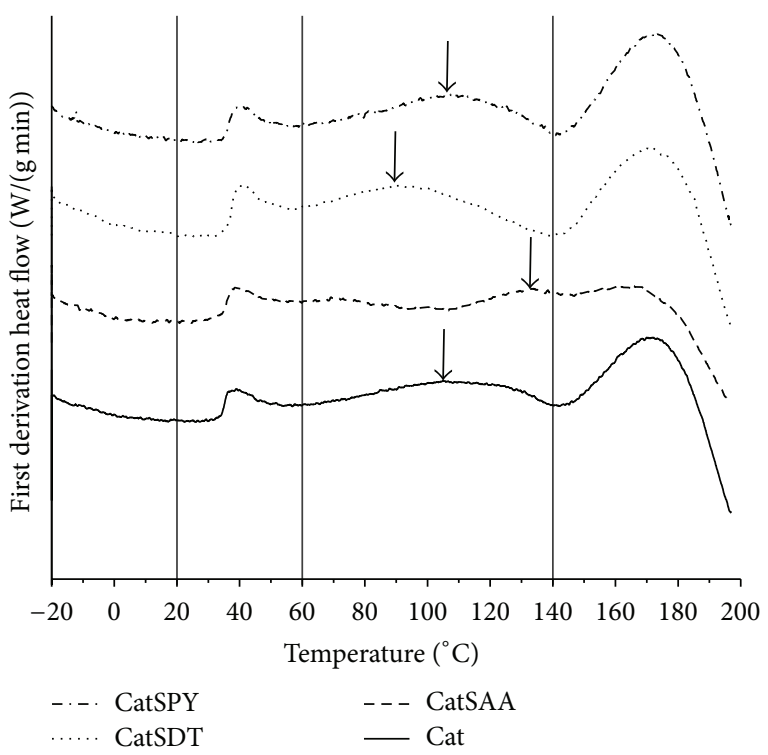

Figure 3: Endothermic heat flow curves (first derivation) of differential scanning analyses of catechol that was enzymatically reacted with laccase in the presence and absence of sulfonamide antibiotics.

peak in the third temperature range from $60^{\circ} \mathrm{C}$ to $140^{\circ} \mathrm{C}$. Clear differences between the different combinations were determined. The maximum for the catechol oligomer without sulfonamide was located at $105^{\circ} \mathrm{C}$; in combination with SPY this maximum was slightly shifted to $108^{\circ} \mathrm{C}$. The difference of $3^{\circ} \mathrm{C}$ is negligible and therefore we concluded that bound SPY had no effect on the rigidity of the catechol oligomer. When SAA was present, the maximum was clearly shifted towards higher temperatures $\left(133^{\circ} \mathrm{C}\right)$. This suggests a stabilization of the catechol oligomer through SAA. We assume that the formation of bound residues occurred via both $\mathrm{NH}_{2}$-groups making SAA a bridge within the oligomeric network of the substituted phenol. It is suggested that a similar transformation of the $\mathrm{NH}_{2}$-group occurred as it was determined by ${ }^{15} \mathrm{~N}$ NMR for SPY and vanillin. In combination with SDT the transition temperature was reduced to $90^{\circ} \mathrm{C}$, indicating a plasticizer effect of SDT on the oligomeric structure. This effect is not related to unreacted SDT, since no signal was determined at the step transition temperature of pure SDT of $66^{\circ} \mathrm{C}$ [55]. Hence it is concluded that SDT was at least reversibly adsorbed to the phenolic oligomer, as it was shown by the sequential extraction procedure (Section 3.2). The decomposition of structures is indicated by an endothermic peak in the fourth range above $140^{\circ} \mathrm{C}$. In this range the thermograms show a similar curve shape for all investigated catechol structures. There is no clear distinction between the various combinations.

\section{Conclusions}

The results presented show that sulfonamides are immobilized upon humification processes that were investigated using substituted phenols as model humic monomers and the enzyme laccase. The sulfonamides were especially transformed in the presence of enzymatically reacted substituted 
phenols but also abiotic transformation was determined in the presence of substituted phenols alone. The mechanisms of immobilization varied from reversible adsorption to the formation of nonextractable bound residues most probably through cross coupling of SPY and vanillin via the aniline$\mathrm{N}$ of the sulfonamide. The extent of each mechanism varied with the physicochemical properties of the sulfonamide and substituted phenol tested, respectively. On the one hand, it must be expected that the mechanisms determined in these model experiments are valid for field soils as well since phenolic and quinoid groups are also contained in large number in soil humic substances and oxidoreductases such as laccase are widespread in the environment. Covalently bound residues were formed and, based on nonextractability, might make up 6 to $79 \%$ of the spiked amount of sulfonamides. With no doubt, the bound residues are less bioactive than the parent compound. On the other hand, the extent of each mechanism varied between model experiments. Consequently the binding mechanisms and ecological relevance of sulfonamide residues remaining in field soil may also vary upon the specific conditions at different sites.

\section{Abbreviations}

$\begin{array}{ll}\text { Cat: } & \text { Catechol } \\ \text { Gua: } & \text { Guaiacol } \\ \text { Van: } & \text { Vanillin } \\ \text { SAA: } & \text { Sulfanilamide } \\ \text { SDT: } & \text { Sulfadimethoxine } \\ \text { SPY: } & \text { Sulfapyridine } \\ \text { DMSO: } & \text { Dimethyl sulfoxide } \\ \text { DSC: } & \text { Differential scanning calorimetry } \\ \text { HPLC: } & \text { High performance liquid } \\ & \text { chromatography } \\ { }^{15} \text { N CPMAS NMR: } & \text { Solid state cross polarization magic } \\ & \text { angle spinning nitrogen-15 nuclear } \\ & \text { magnetic resonance. }\end{array}$

\section{Conflict of Interests}

The authors declare that there is no conflict of interests regarding the publication of this paper.

\section{Authors' Contribution}

J. Schwarz and S. Thiele-Bruhn contributed equally to this work. H. Knicker did the work on ${ }^{15} \mathrm{~N}$ CPMAS NMR while differential scanning calorimetry was done by G. E. Schaumann.

\section{Acknowledgment}

This project was funded by the German Research Foundation (DFG Th 678/4-1 and DFG Th 678/4-2).

\section{References}

[1] A. B. Boxall, L. A. Fogg, P. A. Blackwell, P. Kay, E. J. Pemberton, and A. Croxford, "Veterinary medicines in the environment," Reviews of environmental contamination and toxicology, vol. 180, pp. 1-91, 2004.

[2] K.-R. Kim, G. Owens, S.-I. Kwon, K.-H. So, D.-B. Lee, and Y. S. Ok, "Occurrence and environmental fate of veterinary antibiotics in the terrestrial environment," Water, Air, and Soil Pollution, vol. 214, no. 1-4, pp. 163-174, 2011.

[3] G. Hamscher, H. T. Pawelzick, H. Höper, and H. Nau, "Different behavior of tetracyclines and sulfonamides in sandy soils after repeated fertilization with liquid manure," Environmental Toxicology and Chemistry, vol. 24, no. 4, pp. 861-868, 2005.

[4] H. Schmitt, H. Haapakangas, and P. Van Beelen, "Effects of antibiotics on soil microorganisms: time and nutrients influence pollution-induced community tolerance," Soil Biology and Biochemistry, vol. 37, no. 10, pp. 1882-1892, 2005.

[5] P. Sukul and M. Spiteller, "Sulfonamides in the environment as veterinary drugs," Reviews of Environmental Contamination and Toxicology, vol. 187, pp. 67-101, 2006.

[6] T. Müller, I. Rosendahl, A. Focks, J. Siemens, J. Klasmeier, and M. Matthies, "Short-term extractability of sulfadiazine after application to soils," Environmental Pollution, vol. 172, pp. 180185, 2013.

[7] Q. Wang, M. Guo, and S. R. Yates, "Degradation kinetics of manure-derived sulfadimethoxine in amended soil," Journal of Agricultural and Food Chemistry, vol. 54, no. 1, pp. 157-163, 2006.

[8] S. Thiele-Bruhn and D. Peters, "Photodegradation of pharmaceutical antibiotics on slurry and soil surfaces," Landbauforschung Völkenrode, vol. 57, no. 1, pp. 13-23, 2007.

[9] T. Junge, K. C. Meyer, K. Ciecielski, A. Adams, A. Schaffer, and B. Schmidt, "Characterization of non-extractable ${ }^{14} \mathrm{C}$ - and ${ }^{13} \mathrm{C}$ sulfadiazine residues in soil including simultaneous amendment of pig manure," Journal of Environmental Science and Health. Part. B, Pesticides, Food Contaminants, and Agricultural Wastes, vol. 46, no. 2, pp. 137-149, 2011.

[10] B. Schmidt, J. Ebert, M. Lamshöft et al., "Fate in soil of ${ }^{14} \mathrm{C}$ sulfadiazine residues contained in the manure of young pigs treated with a veterinary antibiotic," Journal of Environmental Science and Health Part B: Pesticides, Food Contaminants, and Agricultural Wastes, vol. 43, no. 1, pp. 8-20, 2008.

[11] R. Kreuzig and S. Höltge, "Investigations on the fate of sulfadiazine in manured soil: laboratory experiments and Test Plot Studies," Environmental Toxicology and Chemistry, vol. 24, no. 4, pp. 771-776, 2005.

[12] K. Stoob, H. P. Singer, S. Stettler, N. Hartmann, S. R. Müller, and C. H. Stamm, "Exhaustive extraction of sulfonamide antibiotics from aged agricultural soils using pressurized liquid extraction," Journal of Chromatography A, vol. 1128, no. 1-2, pp. 1-9, 2006.

[13] M. Förster, V. Laabs, M. Lamshöft, T. Pütz, and W. Amelung, "Analysis of aged sulfadiazine residues in soils using microwave extraction and liquid chromatography tandem mass spectrometry," Analytical and Bioanalytical Chemistry, vol. 391, no. 3, pp. 1029-1038, 2008.

[14] H.-R. Schulten and M. Schnitzer, "The chemistry of soil organic nitrogen:a review," Biology and Fertility of Soils, vol. 26, no. 1, pp. $1-15,1998$. 
[15] N. Senesi, B. Xing, and P. M. Huang, Biophysico-Chemical Processes Involving Natural Nonliving Organic Matter in Environmental Systems, John Wiley \& Sons, Hoboken, NJ, USA, 2009.

[16] J. M. Bracewell, K. Haider, S. R. Larter, and H. R. Schulten, "Thermal degradation relevant to structural studies of humic substances," in Humic Substances II: In Search of Structure, M. H. B. Hayes, P. MacCarthy, R. L. Malcolm, and R. S. Swift, Eds., pp. 181-222, John Wiley \& Sons, New York, NY, USA, 1989.

[17] J. M. Suflita and J.-M. Bollag, "Polymerization of phenoliccompounds by a soil-enzyme complex," Soil Science Society of America Journal, vol. 45, pp. 297-302, 1981.

[18] S. B. Haderlein and R. P. Schwarzenbach, "Environmental processes influencing the rate of abiotic reduction of nitroaromatic compounds in the subsurface," in Biodegradation of Nitroaromatic Compounds, J. C. Spain, Ed., pp. 199-225, Plenum Press, New York, NY, USA, 1995.

[19] J. M. Bollag, "Decontaminating soil with enzymes: an in situ method using phenolic and anilinic compounds," Environmental Science and Technology, vol. 26, no. 10, pp. 1876-1881, 1992.

[20] J. Schwarz, M.-O. Aust, and S. Thiele-Bruhn, "Metabolites from fungal laccase-catalysed transformation of sulfonamides," Chemosphere, vol. 81, no. 11, pp. 1469-1476, 2010.

[21] H. M. Bialk, A. J. Simpson, and J. A. Pedersen, "Cross-coupling of sulfonamide antimicrobial agents with model humic constituents," Environmental Science and Technology, vol. 39, no. 12, pp. 4463-4473, 2005.

[22] H. M. Bialk, C. Hedman, A. Castillo, and J. A. Pedersen, "Laccase-mediated Michael addition of $15 \mathrm{~N}$-sulfapyridine to a model humic constituent," Environmental Science and Technology, vol. 41, no. 10, pp. 3593-3600, 2007.

[23] H. M. Bialk and J. A. Pedersen, "NMR investigation of enzymatic coupling of sulfonamide antimicrobials with humic substances," Environmental Science and Technology, vol. 42, no. 1, pp. 106-112, 2008.

[24] A. Gulkowska, B. Thalmann, J. Hollender, and M. Krauss, "Nonextractable residue formation of sulfonamide antimicrobials: new insights from soil incubation experiments," Chemosphere, vol. 107, pp. 366-372, 2014.

[25] A. Gulkowska, M. Krauss, D. Rentsch, and J. Hollender, "Reactions of a sulfonamide antimicrobial with model humic constituents: assessing pathways and stability of covalent bonding," Environmental Science and Technology, vol. 46, no. 4, pp. 21022111, 2012.

[26] A. Gulkowska, M. Sander, J. Hollender, and M. Krauss, "Covalent binding of sulfamethazine to natural and synthetic humic acids: assessing laccase catalysis and covalent bond stability," Environmental Science and Technology, vol. 47, no. 13, pp. 69166924, 2013.

[27] A. Gulkowska, J. Hollender, and M. Krauss, "Covalent bonding of sulfonamide antimicrobials with organic matter: dominance of nucleophilic addition over radical coupling," in Proceedings of the SETAC Europe 20th Annual Meeting, Sevilla, Spain, May 2010.

[28] F. J. González-Vila, F. Martin, C. Sáiz-Jiménez, and H. H. Nimz, "Thermofractography of humic substances," Journal of Thermal Analysis, vol. 15, no. 2, pp. 279-284, 1979.

[29] P. Baldrian, "Fungal laccases-occurrence and properties," FEMS Microbiology Reviews, vol. 30, no. 2, pp. 215-242, 2006.

[30] C.-J. Wang, S. Thiele, and J.-M. Bollag, "Interaction of 2,4,6trinitrotoluene (TNT) and 4-amino-2,6-dinitrotoluene with humic monomers in the presence of oxidative enzymes," Archives of Environmental Contamination and Toxicology, vol. 42, no. 1, pp. 1-8, 2002.

[31] J.-E. Kim, E. Fernandes, and J.-M. Bollag, "Enzymatic coupling of the herbicide bentazon with humus monomers and characterization of reaction products," Environmental Science and Technology, vol. 31, no. 8, pp. 2392-2398, 1997.

[32] S. Thiele, E. Fernandes, and J. M. Bollag, "Enzymatic transformation and binding of labeled 2,4,6-trinitrotoluene to humic substances during an anaerobic/aerobic incubation," Journal of Environmental Quality, vol. 31, no. 2, pp. 437-444, 2002.

[33] S. Thiele-Bruhn and M.-O. Aust, "Effects of pig slurry on the sorption of sulfonamide antibiotics in soil," Archives of Environmental Contamination and Toxicology, vol. 47, no. 1, pp. 31-39, 2004.

[34] H. Knicker, D. Bruns-Nagel, O. Drzyzga, E. Von Löw, and K. Steinbach, "Characterization of ${ }^{15} \mathrm{~N}$-TNT residues after an anaerobic/aerobic treatment of soil/molasses mixtures by solidstate ${ }^{15} \mathrm{~N}$ NMR spectroscopy. 1. Determination and optimization of relevant NMR spectroscopic parameters," Environmental Science and Technology, vol. 33, no. 2, pp. 343-349, 1999.

[35] G. E. Schaumann and E. J. LeBoeuf, "Glass transitions in peat: their relevance and the impact of water," Environmental Science and Technology, vol. 39, no. 3, pp. 800-806, 2005.

[36] J. Hurrass and G. E. Schaumann, "Is glassiness a common characteristic of soil organic matter?" Environmental Science and Technology, vol. 39, no. 24, pp. 9534-9540, 2005.

[37] H. R. Christen, Grundlagen der Organischen Chemie, Salle \& Sauerländer, Frankfurt, Germany, 6th edition, 1985.

[38] A. L. Boreen, W. A. Arnold, and K. McNeill, “Triplet-sensitized photodegradation of sulfa drugs containing six-membered heterocyclic groups: identification of an $\mathrm{SO}_{2}$ extrusion photoproduct," Environmental Science and Technology, vol. 39, no. 10, pp. 3630-3638, 2005.

[39] A. L. Boreen, W. A. Arnold, and K. McNeill, "Photodegradation of pharmaceuticals in the aquatic environment: a review," Aquatic Sciences, vol. 65, no. 4, pp. 320-341, 2003.

[40] A. L. Boreen, W. A. Arnold, and K. McNeill, "Photochemical fate of sulfa drugs in then aquatic environment: sulfa drugs containing five-membered heterocyclic groups," Environmental Science and Technology, vol. 38, no. 14, pp. 3933-3940, 2004.

[41] P. Sukul, M. Lamshöft, S. Zühlke, and M. Spiteller, "Photolysis of 14C-sulfadiazine in water and manure," Chemosphere, vol. 71, no. 4, pp. 717-725, 2008.

[42] W. Tappe, M. Herbst, D. Hofmann et al., "Degradation of sulfadiazine by Microbacterium lacus strain SDZm4, isolated from lysimeters previously manured with slurry from sulfadiazinemedicated pigs," Applied and Environmental Microbiology, vol. 79, no. 8, pp. 2572-2577, 2013.

[43] M. J. García-Galán, M. Silvia Díaz-Cruz, and D. Barceló, "Identification and determination of metabolites and degradation products of sulfonamide antibiotics," TrAC-Trends in Analytical Chemistry, vol. 27, no. 11, pp. 1008-1022, 2008.

[44] S. Camarero, D. Ibarra, M. J. Martínez, and Á. T. Martínez, "Lignin-derived compounds as efficient laccase mediators for decolorization of different types of recalcitrant dyes," Applied and Environmental Microbiology, vol. 71, no. 4, pp. 1775-1784, 2005.

[45] J. Schwarz, S. Thiele-Bruhn, K.-U. Eckhardt, and H.-R. Schulten, "Sorption of sulfonamide antibiotics to soil organic sorbents: batch experiments with model compounds and computational 
chemistry," ISRN Soil Science, vol. 2012, Article ID 159189, 10 pages, 2012.

[46] P. S. Guin, S. Das, and P. C. Mandal, "Electrochemical reduction of quinones in different media: a review," International Journal of Electrochemistry, vol. 2011, Article ID 816202, 22 pages, 2011.

[47] S.-F. Yang, C.-F. Lin, A. Yu-Chen Lin, and P.-K. Andy Hong, "Sorption and biodegradation of sulfonamide antibiotics by activated sludge: experimental assessment using batch data obtained under aerobic conditions," Water Research, vol. 45, no. 11, pp. 3389-3397, 2011.

[48] M. Förster, V. Laabs, M. Lamshöft et al., "Sequestration of manure-applied sulfadiazine residues in soils," Environmental Science and Technology, vol. 43, no. 6, pp. 1824-1830, 2009.

[49] S. Thiele-Bruhn, T. Seibicke, H. R. Schulten, and P. Leinweber, "Sorption of sulfonamide pharmaceutical antibiotics on whole soils and particle-size fractions," Journal of Environmental Quality, vol. 33, no. 4, pp. 1331-1342, 2004.

[50] G. Fåhraeus and B. Reinhammar, "Large scale production and purification of laccase from cultures of the fungus Polyporus versicolor and some properties of laccase A," Acta Chemica Scandinavica, vol. 21, no. 9, pp. 2367-2378, 1967.

[51] H. Knicker, G. Almendros, F. J. González-Vila, F. Martin, and H.-D. Lüdemann, " ${ }^{13} \mathrm{C}$ - and ${ }^{15} \mathrm{~N}-\mathrm{NMR}$ spectroscopic examination of the transformation of organic nitrogen in plant biomass during thermal treatment," Soil Biology and Biochemistry, vol. 28, no. 8, pp. 1053-1060, 1996.

[52] A. E. Berns, H. Philipp, and H. Lewandowski, "Elucidating the reaction of sulfadiazine with soil humic acid with ${ }^{15} \mathrm{~N}$-CPMASNMR spectroscopy," in Proceedings of the EUROSOIL: SoilSociety-Environment Conference, p. 9, European Geosciences Union, Vienna, Austria, 2008.

[53] E. J. LeBoeuf and L. Zhang, "Thermal analysis for advanced characterization of natural nonliving organic materials," Biophysico-Chemical Processes Involving Natural Nonliving Organic Matter in Environmental Systems, pp. 783-836, 2009.

[54] G. E. Schaumann, E. J. LeBoeuf, R. Delapp, and J. Hurraß, "Thermomechanical analysis of air-dried whole soil samples," Thermochimica Acta, vol. 436, no. 1-2, pp. 83-89, 2005.

[55] E. Fukuoka, M. Makita, and S. Yamamura, "Glassy state of pharmaceuticals. III. Thermal properties and stability of glassy pharmaceuticals and their binary glass systems," Chemical and Pharmaceutical Bulletin, vol. 37, no. 4, pp. 1047-1050, 1989. 

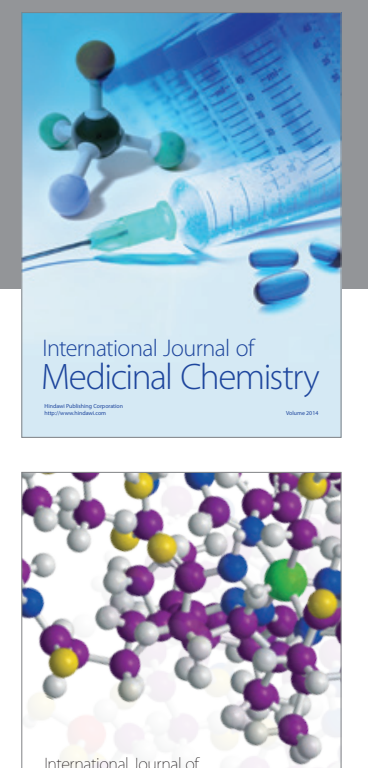

\section{Carbohydrate} Chemistry

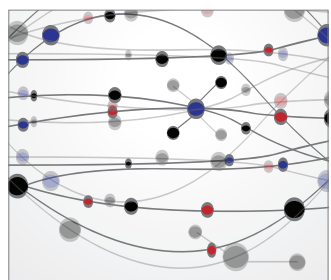

The Scientific World Journal
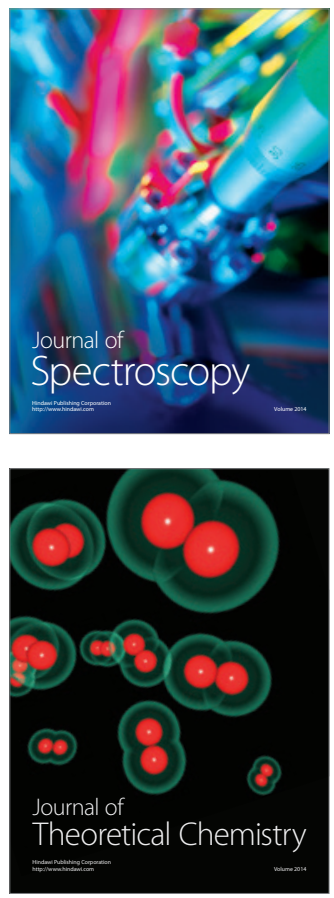
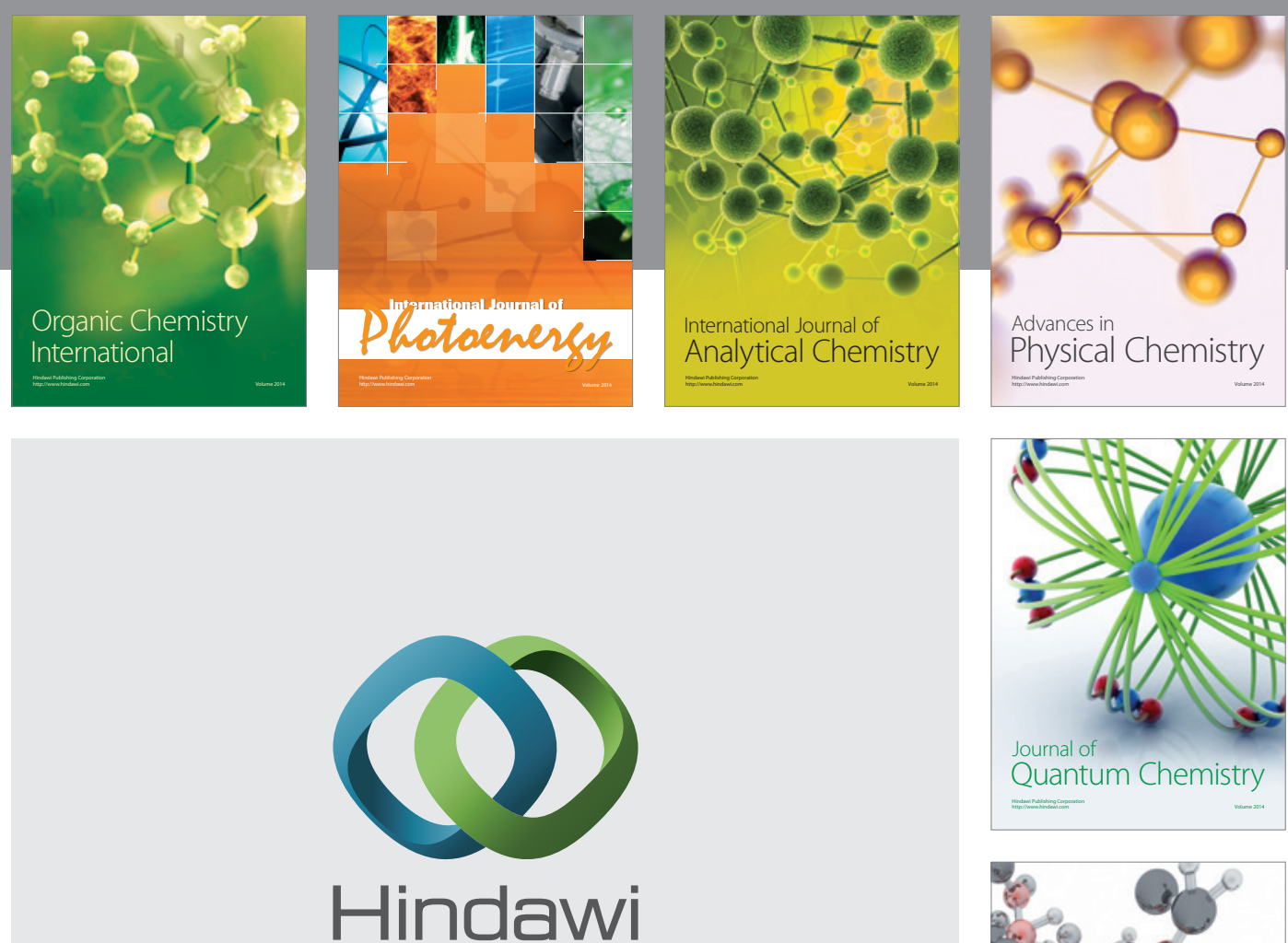

Submit your manuscripts at

http://www.hindawi.com

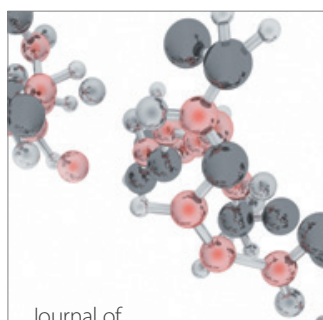

Analytical Methods

in Chemistry

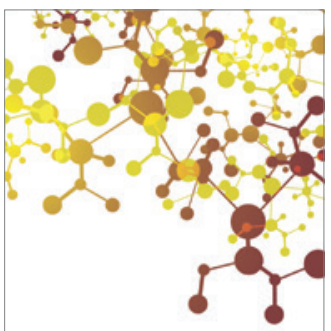

Journal of

Applied Chemistry

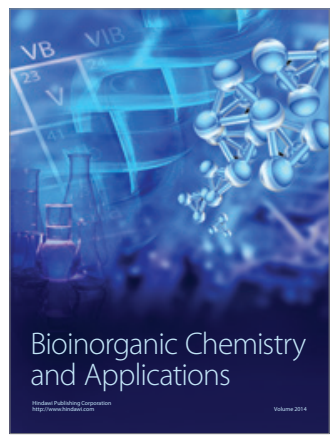

Inorganic Chemistry
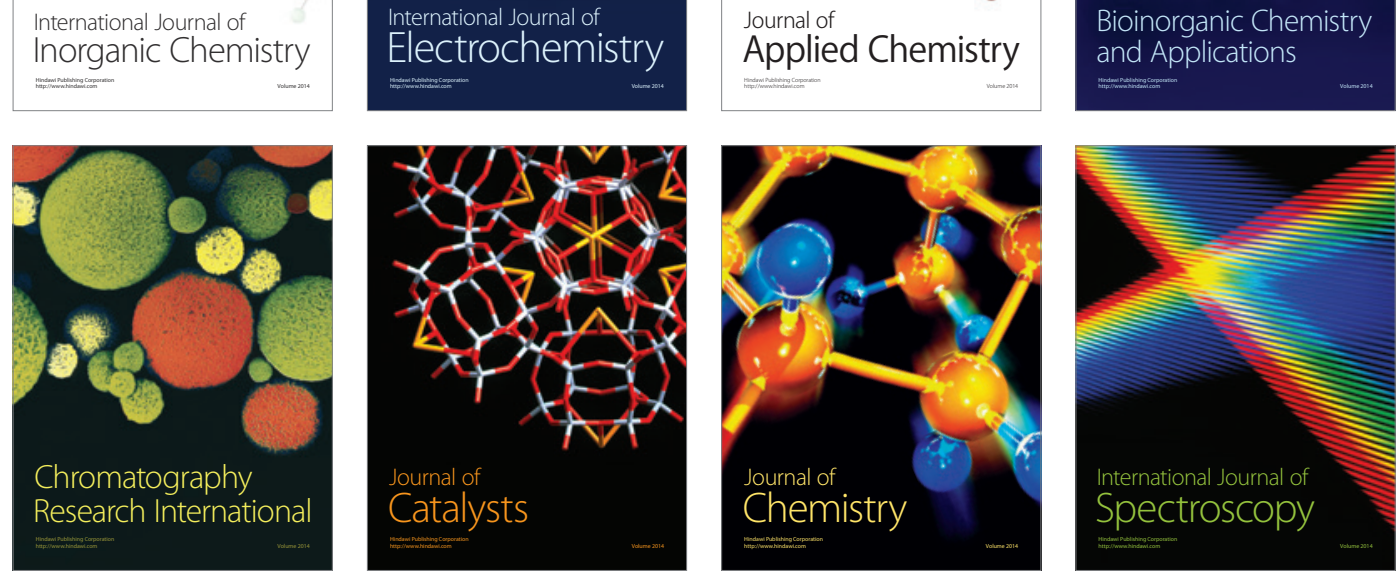